\title{
O Sistema de Gestão Ambiental como ferramenta didática e de adequação ambiental do IFCE - campus Juazeiro do Norte
}

\section{Environmental Management System as a mechanism for teaching and environmental adequacy at IFCE - campus Juazeiro do Norte}

\author{
Joelma Lima Oliveira ${ }^{a}$ \\ Mailodovinci de Sousa Pereira ${ }^{b}$ \\ Janderson Cabral Barbosa ${ }^{\mathrm{c}}$ \\ Uriel Pereira da Silva Barbosa ${ }^{d}$ \\ Letícia Lacerda Freire ${ }^{\mathrm{e}}$ \\ Ana Beatriz Batista de Almeida ${ }^{\dagger}$ \\ Monique da Silva Albuquerque ${ }^{g}$
}

a Instituto Federal de Educação, Ciência e Tecnologia do Ceará - Campus Juazeiro do Norte. Docente do Curso de Bacharelado em Engenharia Ambiental; Tecnóloga em Saneamento Ambiental; Mestra em Engenharia Civil. E-mail: joelma.oliveira@ifce.edu.br

b Instituto Federal de Educação, Ciência e Tecnologia do Ceará - Campus Juazeiro do Norte. Discente do Curso de Bacharelado em Engenharia Ambiental. E-mail: mailodovinc@gmail.com

c Instituto Federal de Educação, Ciência e Tecnologia do Ceará - Campus Juazeiro do Norte. Discente do Curso de Bacharelado em Engenharia Ambiental. E-mail: j.anderson.cabral1@gmail.com

d Instituto Federal de Educação, Ciência e Tecnologia do Ceará - Campus Juazeiro do Norte. Discente do Curso de Bacharelado em Engenharia Ambiental. E-mail: urielbarbosa46@gmail.com

e Bacharel em Engenharia Ambiental e Sanitária pelo Instituto Federal de Educação, Ciência e Tecnologia do Ceará - Campus Juazeiro do Norte; Técnica de Laboratório em Meio Ambiente do IFCE - Campus Sobral. Email: leticia.freire@ifce.edu.br

f Instituto Federal de Educação, Ciência e Tecnologia do Ceará - Campus Juazeiro do Norte. Discente do Curso de Bacharelado em Engenharia Ambiental. E-mail: almeidabeatriz993@gmail.com

9 Instituto Federal de Educação, Ciência e Tecnologia do Ceará - Campus Juazeiro do Norte. Discente do Curso de Bacharelado em Engenharia Ambiental. E-mail: monique.albuquerque1996@gmail.com

Recebido em: 21/05/2018 I Aceito em:29/06/2018 


\section{ARTIGO}

\section{RESUMO}

A limitação de recursos naturais e as restrições definidas pelas legislações ambientais estimulam mecanismos de gestão capazes de reduzir passivos ambientais e aumentar a lucratividade de empreendimentos, através do uso racional de insumos. Neste âmbito, as certificações da ISO 14001 têm promovido, através de metodologia que associa ações e verificações de efetividade, a garantia da adequação ambiental das instituições. Contudo, a implantação de sistemas de gestão ambiental também tem sido adotada em órgãos e instituições públicas, especialmente devido às exigências da Portaria $n^{\circ} 61 / 08$ do Ministério do Meio Ambiente e a Agenda Ambiental da Administração Pública (A3P). Haja vista a grande demanda por insumos ambientais e a geração de resíduos sólidos e rejeitos, as instituições de ensino superior devem direcionar esforços no sentido de mitigar seus impactos. Nesse contexto, este estudo propôs-se a divulgar as ações e resultados obtidos com a implantação de Sistema de Gestão Ambiental no Instituto Federal de Educação, Ciência e Tecnologia do Ceará (IFCE) campus Juazeiro do Norte. Verificou-se maior controle sobre a qualidade de recursos hídricos, a adoção de solução para resíduos orgânicos por meio do processo de compostagem, e encaminhamento de resíduos sólidos recicláveis para Associação de Catadores e uma redução em cerca de $16 \%$ do consumo energético, além de verificações de inconformidades ambientais.

Palavras-chave: Recursos naturais. Sistema de Gestão Ambiental. Instituição de Ensino Superior.

\section{ABSTRACT}

The scarcities of environmental resources and legal environmental restrictions have stimulated management mechanisms capable of reducing environmental passives and enhancing business profit. Regard to this, ISO 14001 certifications have promoted businesses environmental adequacy, through a methodological approach that involves corrective actions and efficiency analysis. However, environmental management systems have also been adopted by public organizations, due to the requirements of the Environment Ministry and the Public Administration Environmental Schedule. Given the large demand for environmental resources and the generation of solid wastes in Bachelor Degree Institutions, these universities must mitigate their environmental impacts. In this context, this study aims to transmit 
the actions and results obtained after the establishment of an Environmental Management System at IFCE campus Juazeiro do Norte. As benefits, the institution acquired better control of water resources quality, organic wastes solution by composting process, donation of solid wastes to pickers association and reduction of approximately $16 \%$ of electric energy consumption, in addition to environmental nonattendances verifications.

Key-words: Natural Resources. Environmental Management System. Universities.

\section{INTRODUÇÃO}

A transição da concepção antropocêntrica em relação aos serviços ambientais para a adoção de conceitos ecocêntricos tem sido motivada pelo esgotamento ou comprometimento qualitativo dos recursos naturais. Como observado por MUELLER (2004), a expansão do sistema econômico global a partir de 1950 exigiu significativa demanda por recursos naturais e acentuou a geração de rejeitos perigosos. As décadas seguintes foram acompanhadas de relativa atenção à dimensão ambiental nas análises econômicas, motivada pelo aumento da poluição no primeiro mundo na década de 60 , a crise do petróleo nos anos 70 e o relatório do clube de Roma, o qual discutia os limites naturais impostos ao crescimento econômico e demográfico, através de simulações computacionais (MUELLER,1998). Direcionaram-se esforços, portanto, no âmbito da adequação ambiental dos processos produtivos, intencionando-se evitar as adversidades provenientes de severa depleção de recursos ambientais.

Em se tratando de alterações administrativas para promoção da adequação ambiental, introduz-se a gestão ambiental a qual, consoante definição de ROSA (2013), refere-se à administração voltada ao atendimento de metas ambientais em face às demandas sociais e progressiva indisponibilidade de recursos. As ações desenvolvidas pela gestão ambiental envolvem o monitoramento, controle e gerenciamento de entradas e saídas de matérias e energia dos processos produtivos, neste âmbito, como ferramenta de efetivação dos objetivos da gestão ambiental, inserem-se os sistemas de gestão ambiental (SGA), cujos requisitos encontram-se na norma ISO 14001. Os sistemas de gestão ambiental atuam no 
Joelma Lima Oliveira; Mailodovinci de Sousa Pereira;

Janderson Cabral Barbosa;

Uriel Pereira da Silva Barbosa;

Letícia Lacerda Freire; Ana Beatriz Batista de Almeida;

Monique da Silva Albuquerque;

gerenciamento de aspectos ambientais, observância de requisitos legais e abordagem de riscos e oportunidades. Os benefícios de sua implantação extrapolam a esfera ambiental, uma vez que também atribuem vantagens econômicas.

Segundo ALBERTON (2003), a existência de um Sistema de Gestão Ambiental contribui para o desempenho ambiental e financeiro das empresas através de projetos, cujos conteúdos almejam a redução de resíduos, o reaproveitamento de resíduos no processo produtivo, além da redução de custos com a aplicação de tecnologias verdes. Como exemplificado por MAGRINI \& POMBO (2008), em panorama de certificações ambientais no Brasil, verificou-se que setores industriais, como o automotivo, petroquímico e químico e o setor de prestação de bens e serviços respondem pela maioria das certificações em conformidade com a ISO 14001. O estudo destaca ainda a região sudeste brasileira por deter 50\% das certificações nacionais. DIAS et al (2008), em estudo de análise do sistema de gestão ambiental da empresa nacional Petrobras, atesta o desenvolvimento econômico da empresa em conjunto com a efetivação da gerência ambiental. No entanto, os autores destacaram a necessidade de serem reduzidos riscos de contaminação ambiental devido a vazamentos acidentais.

Apesar de frequentemente os sistemas de gestão ambiental priorizarem práticas de reaproveitamento de resíduos, por vezes, limitações de ordem tecnológica e econômica tornam a disposição final ambientalmente adequada a única solução viável e, quanto a este aspecto, a preocupação com o atendimento à legislação ambiental vigente assegura às empresas possuidoras de SGA maior segurança na sua conduta ambiental. A Política Nacional de Resíduos Sólidos (lei 12305/10) prevê ainda existência de plano de gerenciamento de resíduos sólidos para geradores cujos resíduos são perigosos ou não se equiparam aos domiciliares, devido a sua natureza ou volume. Deve-se destacar ainda que os dispositivos legais observados pelo SGA dependem dos passivos ambientais gerados pela atividade produtiva. Em relação a controle de emissões atmosféricas, os limites para poluentes atmosféricos estabelecidos pela resolução CONAMA 382/06 devem ser observados, já a respeito de padrões para lançamentos de efluentes, a resolução CONAMA 430/11 deve ser verificada. Limites legais objetivam o desenvolvimento das atividades econômicas em acordo com a manutenção da saúde pública, 
respeitá-los demonstra, portanto, não apenas adequação ambiental, mas responsabilidade para com a saúde da população.

Vale salientar que os benefícios dos sistemas de gestão ambiental, especialmente o controle de informações e a conformidade legal, têm estimulado sua implementação em órgãos e instituições públicas. BARATA, KLIGERMAN \& GOMEZ (2006) propõem que, devido à missão de promover o bem-estar social, as instituições públicas deveriam ser pioneiras na implementação de sistemas ambientais eficientes. Além disso, destacam a utilização racional de recursos financeiros públicos como consequência do uso racional de insumos. Em relação a esse aspecto, a portaria $n^{\circ} 61 / 08$ do Ministério do Meio Ambiente estabelece práticas de sustentabilidade nas compras públicas. Na prática, o documento estabelece a preferência por fornecedores e produtos comprovadamente de menor impacto ambiental, a utilização de correio eletrônico sempre que possível, a escolha de produtos de longa duração, dentre outras medidas. Na esfera da administração pública, há ainda a Agenda Ambiental da Administração Pública (A3P) a qual foi concebida em 1999 e consiste em programa que visa implementar a gestão socioambiental sustentável nas atividades do Estado.

Compondo a administração pública indireta, as instituições de ensino superior públicas são consumidoras em potencial de recursos e seus resíduos podem assumir caráter perigoso, especialmente em instituições onde há cursos nas áreas de saúde. Observando-se, portanto, a exigência legal de se adequarem os insumos e atividades das instituições de Ensino Superior a práticas sustentáveis, a instauração de sistemas de gestão ambiental posiciona-se como mecanismo duradouro de adequação ambiental. No entanto, segundo ENGELMAN (2009), em estudo realizado em instituições do Rio Grande do Sul, verificou-se que a busca por resultados imediatos e indisponibilidade de investimentos para o SGA podem ser obstáculos. Contudo, o autor, em seu estudo, concluiu que em todas as instituições, apesar das limitações financeiras e culturais, havia iniciativas sustentáveis relacionadas às práticas acadêmicas e operacionais das instituições.

Diante da evidente relevância da implementação de Sistemas de Gestão Ambiental em Instituições de Ensino Superior, este estudo reúne informações acerca da instauração de SGA no Instituto Federal de Educação, Ciência e Tecnologia do 
Joelma Lima Oliveira; Mailodovinci de Sousa Pereira;

Janderson Cabral Barbosa;

Uriel Pereira da Silva Barbosa;

Letícia Lacerda Freire; Ana Beatriz Batista de Almeida;

Monique da Silva Albuquerque;

Ceará (IFCE) campus Juazeiro do Norte, abordando as áreas de atuação, as atividades realizadas, assim como os benefícios e desafios à efetivação dos objetivos do SGA. Propõe-se ainda a explanar a importância das atividades de gestão ambiental para acadêmicos do curso de Engenharia Ambiental, haja vista a possibilidade de aplicação prática de conceitos abordados ao longo de sua formação superior.

\section{METODOLOGIA}

2.1 Logística de Implantação e Acompanhamento

A realização das atividades foi instruída pelas indicações da ISO 14001, a qual instrumentaliza os procedimentos pertinentes ao Sistema de Gestão Ambiental, por meio do método do PDCA. A sigla trata de uma sequência de ações baseadas na busca pela melhoria contínua, a partir de uma Política Ambiental pré-definida.

As ações iniciam pelo Planejamento (Plan), com o estabelecimento dos aspectos ambientais, reconhecimento dos requisitos legais, demarcação de objetivos e metas além da organização de programas de atuação para o alcance do planejado. A segunda etapa seria a Execução (Do), com a capacitação e conscientização de todos os envolvidos, os quais devem ser comunicados de reuniões decisórias ou ainda da existência da política ambiental na instituição.

Para identificar pontos potenciais e vulnerabilidades do sistema, é indicada a etapa de Verificação (Check). As não conformidades identificadas devem ser corrigidas a partir de um plano de ação, os resultados obtidos são a base dos planejamentos posteriores.

A Instituição conta com aspectos ambientais diversos, para os meios físico, biótico e antrópico, os quais foram divididos em Eixos de trabalho prioritários, afirmados na Política Ambiental do Campus, por meio de diagnóstico ambiental prévio. É necessário destacar os procedimentos recomendados na Agenda Ambiental da Administração Pública (A3P), os quais também foram considerados na etapa de planejamento e execução, principalmente no tocante à definição de indicadores. 
2.2 Atividades de cada área de atuação

A divisão da equipe do Sistema de Gestão Ambiental ocorrera de modo a compreender os aspectos ambientais significativos das atividades do instituto. Estabeleceu-se os grupos de trabalho a partir das demandas prioritárias voltadas aos recursos utilizados pela instituição, os quais estão distribuídos em quatro eixos de trabalhos, cujas atividades estão indicadas na Figura 01. Apesar de todos apresentarem atividades que os diferenciam, a promoção da educação ambiental é a intersecção de todos esses campos de atuação.

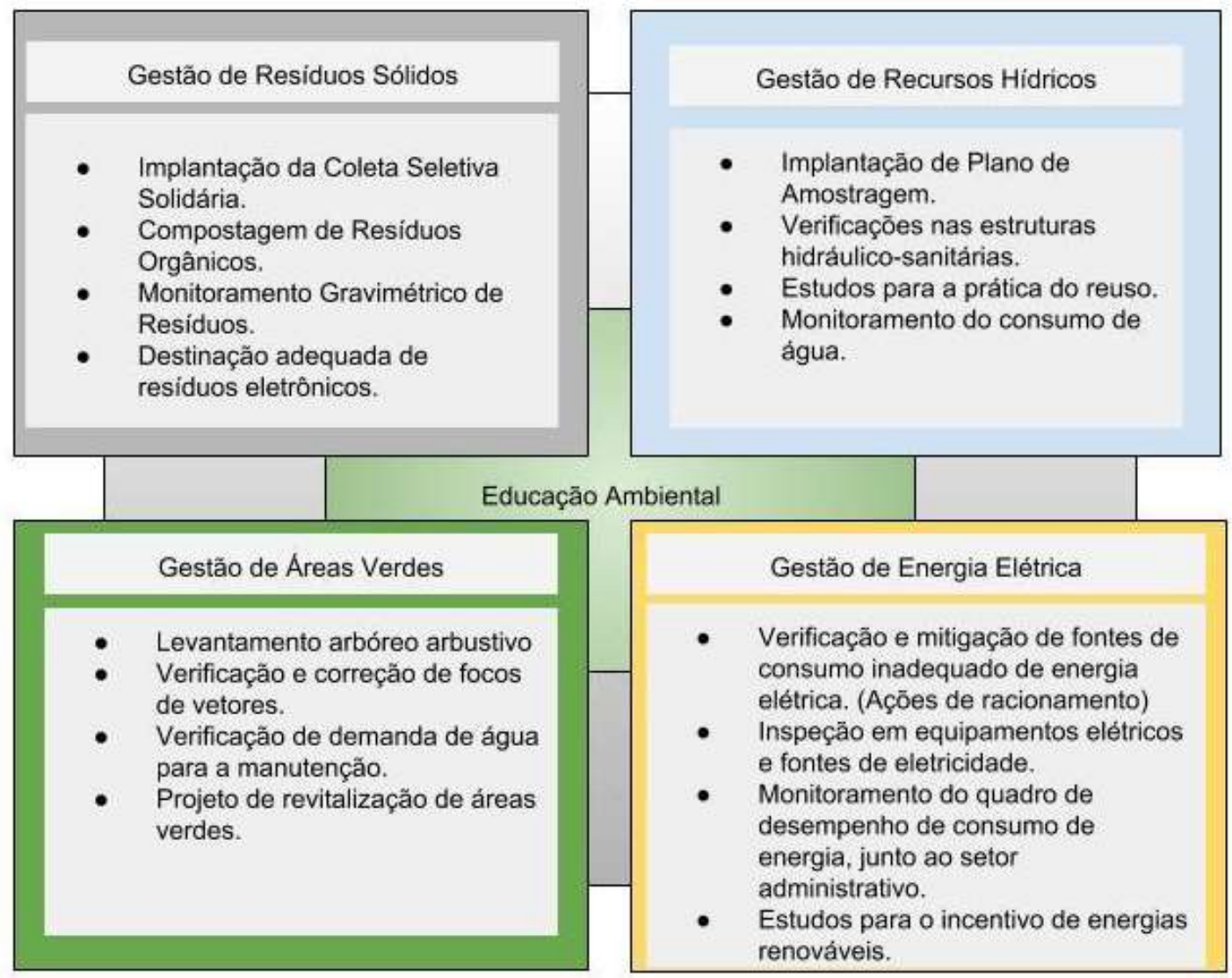

Figura 01: Resumo das atribuições das áreas de gestão.

\section{RESULTADOS E DISCUSSÕES}

A seguir serão apresentadas as ações e resultados de cada campo de atuação do Sistema de Gestão Ambiental, apontando-se os benefícios e desafios verificados. 
Joelma Lima Oliveira; Mailodovinci de Sousa Pereira; Janderson Cabral Barbosa;

Uriel Pereira da Silva Barbosa;

Letícia Lacerda Freire; Ana Beatriz Batista de Almeida;

Monique da Silva Albuquerque;

\subsection{Ações Desenvolvidas na Gestão de Resíduos Sólidos}

\subsubsection{Sistema de Coleta Seletiva}

A instituição possui coletores de resíduos com cores diferenciadas, conforme a Resolução № 275, de 25 de abril de 2001 para implantação da coleta seletiva, conta ainda com grupos de extensão e pesquisa que podem auxiliar no desenvolvimento do Sistema de Gestão Ambiental. Observou-se, portanto, um grande potencial para viabilizar a separação dos resíduos sólidos.

O processo iniciou com a capacitação dos responsáveis pelo setor de serviços gerais, quanto à separação dos resíduos, visto que no início da implantação do sistema, os alunos do campus não estariam totalmente inseridos, havendo ainda algumas problemáticas, passíveis de solução no momento da triagem.

Os materiais recolhidos passaram a ser triados a partir do dia 05 de Junho de 2017. A Associação de Catadores de Materiais Recicláveis - Engenho do Lixo foi acionada para realizar a coleta do material com periodicidade quinzenal, visto que o ambiente de armazenamento comporta o volume gerado por esse período de tempo, podendo haver alteração da data de coleta, desde que comunicada previamente à associação (Figura 02). A ação foi desenvolvida em consonância ao indicado pelo Decreto №5.940 de 2006, o qual estabelece a coleta seletiva solidária para as instituições públicas federais.

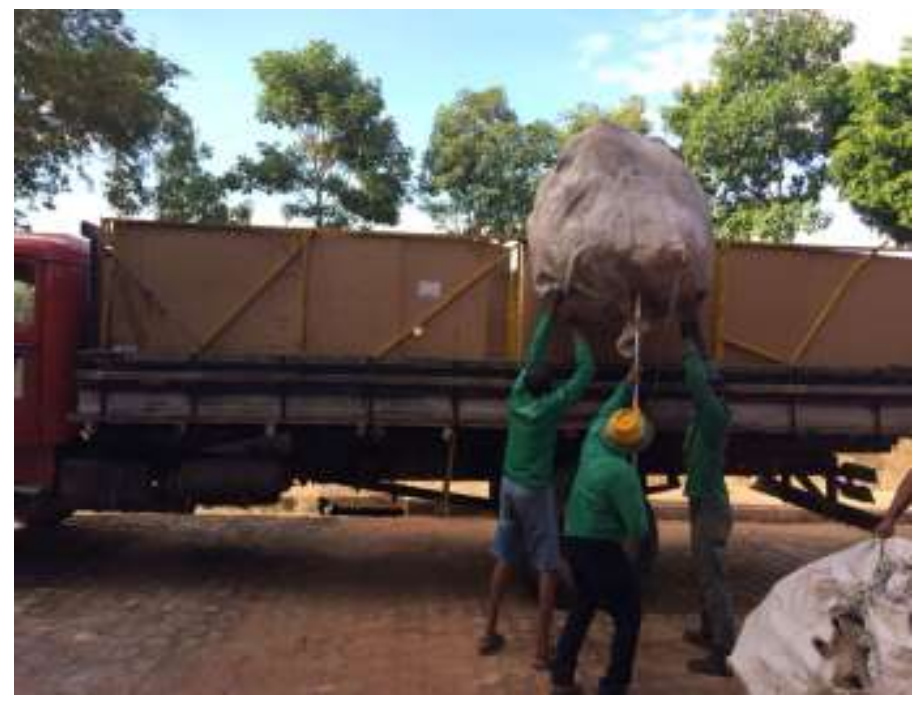

Figura 02: Coleta dos Resíduos pela Associação de Catadores de Materiais Recicláveis. 
Nos primeiros dias de coleta de material, foi observado que apesar de haver as lixeiras diferenciadas para separação de resíduos, a população geradora não as utilizava adequadamente, tendo como consequência a produção de muitos rejeitos. Infelizmente, esta dificuldade, embora reduzida, ainda perdura no atual período operacional do SGA.

Como mecanismo para superação dessas adversidades, inicialmente foram desenvolvidas campanhas de educação ambiental, a partir de divulgação em meios digitais (Figura 03), mas foi observada a necessidade de comunicação direta aos discentes. A última campanha consistiu de comunicação em todas as salas nos turnos da manhã e tarde, intencionando-se a difusão da existência da coleta seletiva no campus e da ocorrência de destinação adequada dos resíduos.

A Figura 03 resume o total de resíduos encaminhados à associação desde a implantação do SGA até abril de 2018. Conforme informações repassadas pela associação para qual o resíduo é doado, o plástico e o papel possuem uma boa venda no mercado da reciclagem, assim como o metal. O vidro, apesar de ser reciclável, não possui boa saída de mercado, devido ao seu baixo valor de venda e a distância das empresas de reciclagem que realizam a compra do material, sendo a mais próxima em Recife e com um valor de $\mathrm{R} \$ 0,03$ por quilograma. Haja vista o caráter variável dos preços, baseando-se em dados de tabela nacional de preços de produtos recicláveis CEMPRE, a receita total doada pela instituição em materiais foi aproximadamente $R \$ 271,7$ reais (valor equivalente à receita total obtida com a venda ao longo do período de operação da coleta seletiva).

Verifica-se, portanto, que a instauração do SGA na instituição contribuiu ainda para a promoção da responsabilidade social. Conforme destacado por GONÇALVES (2015), a atuação das universidades deve dialogar com os demais segmentos da sociedade, de modo a difundir o conhecimento científico e contribuir para o desenvolvimento humano.

CEREZINI, AMARAL \& POLLI (2016), em estudo para minimização dos impactos de resíduos sólidos em instituições de ensino, destacam que o conhecimento e as ações disseminadas entre o público interno e a comunidade trazem benefícios a todos os envolvidos, havendo melhoria dos serviços prestados. 
Joelma Lima Oliveira; Mailodovinci de Sousa Pereira; Janderson Cabral Barbosa;

Uriel Pereira da Silva Barbosa;

Letícia Lacerda Freire; Ana Beatriz Batista de Almeida;

Monique da Silva Albuquerque;

À semelhança, o controle contínuo dos resíduos gerados no campus Juazeiro do Norte permite a identificação de setores da instituição que mais tem contribuído para a geração de resíduos, facilitando intervenções na fonte geradora.

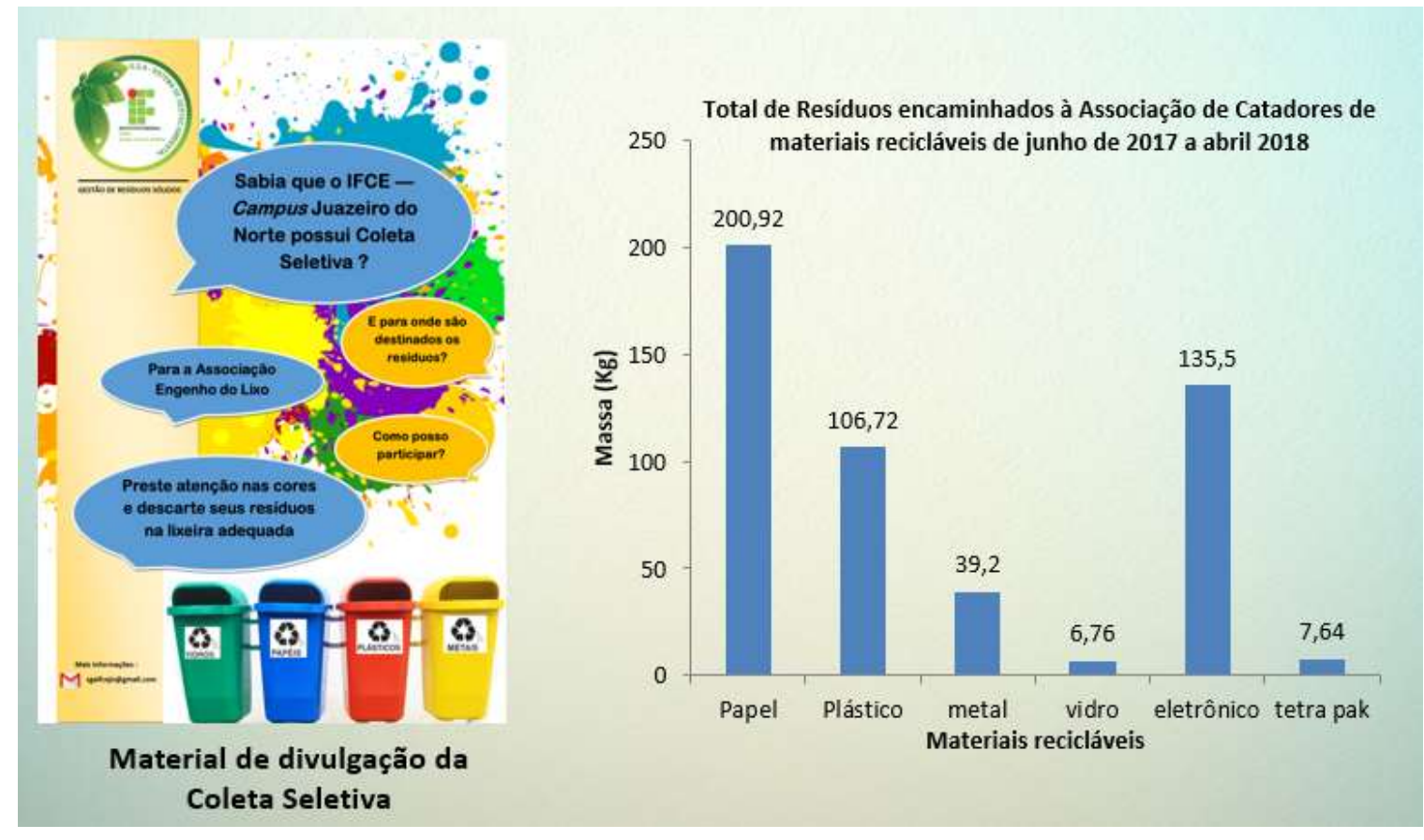

Figura 03: Material de divulgação da coleta seletiva e quantitativo de resíduos encaminhados para reciclagem.

\subsubsection{Compostagem de Resíduos Sólidos Orgânicos}

A Compostagem fora a solução adotada pelo sistema de gestão ambiental para mitigação dos impactos da geração de resíduos orgânicos advindos do restaurante acadêmico. Optou-se por separar resíduos vegetais de carnes na fonte de geração para maior eficiência do processo de compostagem. O transporte e operação do processo são realizados pelos estagiários do SGA, os quais desempenham atividades de monitoramento de temperatura, revolvimento (aeração) e umedecimento. A Figura 04 resume o total de resíduos orgânicos convertidos em adubo de janeiro a abril de 2018. 


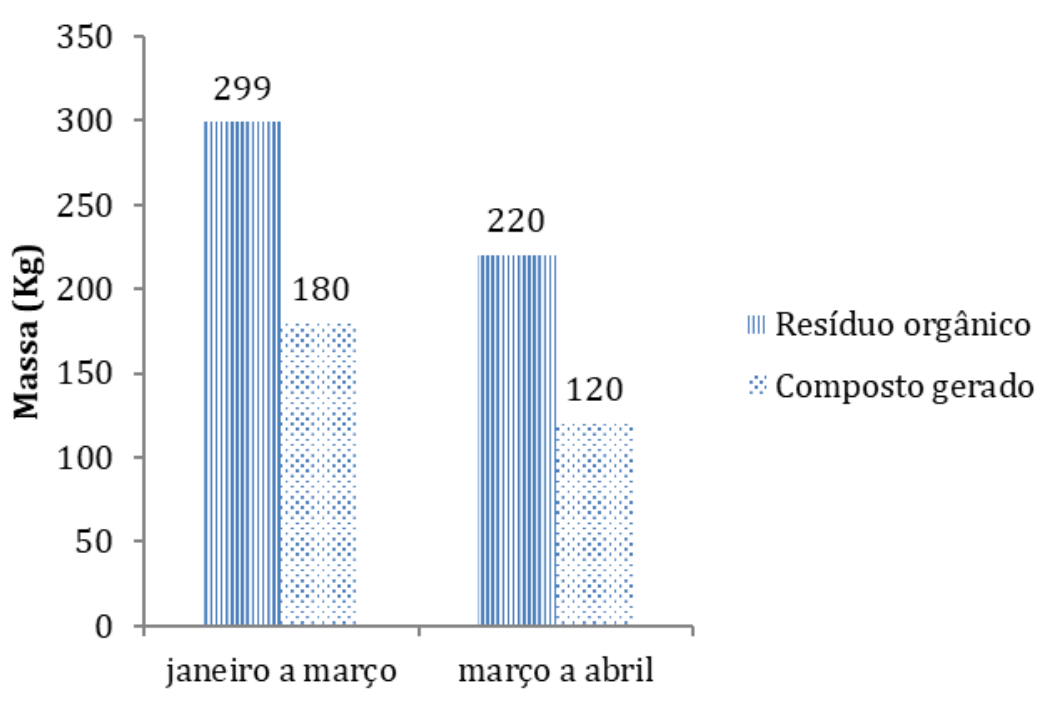

Figura 04: Resíduos orgânicos e quantitativo de composto produzido em 2018.

O composto gerado é destinado para atendimento das demandas de manutenção das áreas verdes do campus e para desenvolvimento de pesquisas. OLIVEIRA, SARTORI \& GARCEZ (2008) afirmaram que a eficiência do processo de compostagem encontra-se entre $1 / 3$ a $1 / 2$, havendo variações quanto ao teor de umidade e resíduos utilizados no processo. Com base nos dados do gráfico, obtevese em média eficiência total de geração de composto de $57,8 \%$.

\subsection{Ações Desenvolvidas na Gestão Energética}

\subsubsection{Trabalho em conjunto com a Comissão Energética do Campus}

Todas as ações realizadas foram planejadas e articuladas com a Comissão Energética do IFCE, composta por discentes e docentes. Através de reuniões, que aconteciam mensalmente, foram traçados objetivos e metas, além de relatórios acerca dos mesmos e medidas corretivas, caso os objetivos não fossem atingidos.

Algumas das ações estabelecidas em conjunto com a Comissão Energética consistiram na substituição de 950 lâmpadas fluorescentes por lâmpadas LED; retirada do excesso de lâmpadas dos corredores de acesso a laboratórios e salas de aula; responsabilidade pelo monitoramento a cargo dos responsáveis pela Gestão Energética do SGA; horário de uso dos aparelhos de ar condicionado, bem como sua temperatura padrão, adotado em $24 \stackrel{\circ}{\circ}$.

Ciência e Sustentabilidade - CeS / Juazeiro do Norte, v. 4, n. 1, p. 115-132, jan/jun - 2018 
Joelma Lima Oliveira; Mailodovinci de Sousa Pereira;

Janderson Cabral Barbosa;

Uriel Pereira da Silva Barbosa;

Letícia Lacerda Freire; Ana Beatriz Batista de Almeida;

Monique da Silva Albuquerque;

\subsubsection{Monitoramento e avaliação}

Com o monitoramento, foram analisados os gastos energéticos dos anos 2016 a 2017, como demonstrado pela Tabela 01, de acordo com as ações previstas em conjunto com a Comissão Energética. Os resultados obtidos foram bastante satisfatórios, uma vez que, desde a implantação do SGA, houve uma redução de $R$ \$ 67.442,81, que representa uma diminuição dos custos energéticos do Campus em 15,7\%. Vale ressaltar que, o mês de Janeiro de 2017 foi atípico, por se tratar de um período de férias, ou seja, sem grandes consumos de energia.

Tabela 01:Contas de Energia da instituição nos anos 2016 e 2017

Conta de Energia do IFCE - Juazeiro do Norte (R\$)

\begin{tabular}{|ccccc|}
\hline Mês & $\mathbf{2 0 1 6}$ & $\mathbf{2 0 1 7}$ & Comparação (2016 e 2017) & $\%$ \\
\hline Janeiro & 38025,48 & 13761,12 & 24264,36 & 63,81 \\
\hline Fevereiro & 28068,41 & 39740,68 & $-11672,27$ & $-41,59$ \\
\hline Março & 36417,07 & 32265,42 & 4151,65 & 11,40 \\
\hline Abril & 34602,71 & 33412,37 & 1190,34 & 3,44 \\
\hline Maio & 36466,82 & 35663,79 & 803,03 & 2,20 \\
\hline Junho & 34378,83 & 32646,35 & 1732,48 & 5,04 \\
\hline Julho & 25641,46 & 21343,35 & 4298,11 & 16,76 \\
\hline Agosto & 37716,06 & 32815,11 & 4900,95 & 12,99 \\
\hline Setembro & 42220,36 & 32311,48 & 9908,88 & 23,47 \\
\hline Outubro & 51904,63 & 40612,92 & 11291,71 & 21,75 \\
\hline Novembro & 46647,38 & 37849,36 & 8798,02 & 18,86 \\
\hline Dezembro & 41278,31 & 33502,76 & 7775,55 & 18,84 \\
\hline Total & 453367,52 & 385924,71 & 67442,81 & 14,88 \\
\hline
\end{tabular}

Quanto às ações de educação ambiental, foram realizadas palestras com o intuito de conscientizar os discentes sobre os gastos energéticos elevados e de que, sem sua participação, a efetividade do cumprimento dos objetivos estabelecidos não seria alcançada. Além disto, foi ministrado um minicurso de SGA, mostrando como 
diminuir o consumo e informando a projeção atual e futura para o Campus, em relação ao orçamento disponível para o custeio de energia elétrica. Cabe destacar que foram fixados panfletos de educação ambiental em locais estratégicos, como nas tomadas e equipamentos de elevado consumo de energia elétrica.

\subsection{Ações do Sistema de Gestão de Recursos Hídricos}

\subsubsection{Plano de Amostragem de água de Abastecimento}

A frequência de análise da água da solução de abastecimento alternativa coletiva do campus fora definida em conformidade com especificações da portaria de consolidação $n^{\circ} 5$ de 28 de setembro de 2017. Os limites observados para parâmetros físico-químicos e microbiológicos seguem o mesmo dispositivo legal. A tabela a seguir apresenta resumidamente a frequência de análises, os pontos de coleta e a quantidade de amostras.

Tabela 02 - Parâmetros e quantidades de amostras do plano de amostragem

\begin{tabular}{|c|c|c|c|c|}
\hline Parâmetro & $\begin{array}{l}\text { Critério para } \\
\text { seleção do ponto } \\
\text { de Coleta }\end{array}$ & Ponto de coleta & $\mathrm{N}^{\circ}$ de amostras & Frequência \\
\hline $\mathrm{Ph}$ & \multirow{12}{*}{$\begin{array}{c}\text { POÇO DE } \\
\text { ABASTECIMENTO } \\
\text { DO INSTITUTO } \\
\text { (ÁGUA BRUTA) }\end{array}$} & \multirow{12}{*}{$\begin{array}{l}\text { PONTO DE } \\
\text { COLETA MAIS } \\
\text { PRÓXIMO DO } \\
\text { POÇO }\end{array}$} & 1 & \\
\hline Cor & & & 1 & \\
\hline Turbidez & & & 1 & \\
\hline $\begin{array}{l}\text { Cloro residual } \\
\text { livre }\end{array}$ & & & 1 & SEMESTRAL \\
\hline Coliformes totais & & & 1 & \\
\hline Escherichia coli & & & 1 & \\
\hline Dureza total & & & 1 & \\
\hline Cloretos & & & 1 & \\
\hline Ferro & & & 1 & \\
\hline Sulfato & & & 1 & \\
\hline Nitrato & & & 1 & \\
\hline $\begin{array}{c}\text { Sólidos } \\
\text { Dissolvidos }\end{array}$ & & & 1 & \\
\hline
\end{tabular}

Tabela 03 - Parâmetros ao longo dos pontos de consumo estratégicos

\begin{tabular}{ccccc}
\hline Parâmetro & $\begin{array}{c}\text { Critério para } \\
\text { seleção do ponto } \\
\text { de Coleta }\end{array}$ & Ponto de coleta & $\mathrm{N}^{\circ}$ de amostras & Frequência \\
\hline
\end{tabular}

Ciência e Sustentabilidade - CeS / Juazeiro do Norte, v. 4, n. 1, p. 115-132, jan/jun - 2018 
Joelma Lima Oliveira; Mailodovinci de Sousa Pereira;

\begin{tabular}{|c|c|c|c|c|}
\hline $\mathrm{Ph}$ & & & 1 & \\
\hline Cor & & & 1 & \\
\hline Turbidez & $\begin{array}{c}\text { PONTOS DE } \\
\text { ABASTECIMENTO }\end{array}$ & $\begin{array}{l}\text { BEBEDOUROS 01, } \\
02 \text { E 03;COZINHA }\end{array}$ & 1 & \\
\hline Cloro residual & $\begin{array}{l}\text { PARA CONSUMO } \\
\text { DIRETO E }\end{array}$ & $\begin{array}{c}\text { DO } \\
\text { RESTAURANTE }\end{array}$ & 1 & TRIMESTRALMENTE \\
\hline $\begin{array}{l}\text { livre } \\
\text { Coliformes totais }\end{array}$ & $\begin{array}{l}\text { PREPARO DE } \\
\text { ALIMENTOS }\end{array}$ & $\begin{array}{l}\text { ACADÉMICO E } \\
\text { COZINHA DA }\end{array}$ & 1 & \\
\hline Escherichia coli & & LANCHONETE & 1 & \\
\hline
\end{tabular}

A partir dos resultados das análises iniciais foi possível constatar que a qualidade físico-química dos recursos hídricos do manancial subterrâneo, uma vez que, para esses parâmetros o diagnóstico inicial pode verificar a concentração de parâmetros em níveis abaixo daqueles estabelecidos legalmente. No entanto, em se tratando de aspectos microbiológicos, a água de abastecimento do campus, apesar de isenta do bioindicador Escherichia coli, apresenta frequentemente presença de coliformes totais, fato que motivou reuniões entre a Gestão de Recursos Hídricos e a direção para análise de possibilidade de instalação de unidade de desinfecção simplificada. A cloração é uma ação exigida pela Portaria n 2.914/2011 para que a água seja fornecida ao consumo humano. Atualmente, o SGA investiga possibilidades economicamente viáveis para apreciação da direção. A tabela a seguir resume os resultados das análises físico-químicas e microbiológicas da água de abastecimento.

O acompanhamento periódico da qualidade de recursos hídricos permite a identificação de inconformidades e consequente busca por ações corretivas. À semelhança, DIAS (2006), relata as mudanças ocorridas com a prática de programa de educação ambiental na Universidade Católica de Brasília, a qual apresentava inconformidades relativas à disposição de resíduos sólidos e desperdícios de recursos hídricos. Avaliações estruturais também são realizadas periodicamente pela equipe de recursos hídricos com o intuito de se identificar pontos de desperdício de recursos hídricos.

Tabela 04- Resultados do laudo de setembro de 2017.

\begin{tabular}{lcccc} 
Parâmetro & $\begin{array}{c}\text { Critério para } \\
\text { seleção do ponto }\end{array}$ & Ponto de coleta & Resultados & Padrões \\
\hline
\end{tabular}




\begin{tabular}{|c|c|c|c|c|}
\hline \multirow{2}{*}{\multicolumn{3}{|c|}{ de Coleta }} & & \\
\hline & & & 6,5 & $6-9,5$ \\
\hline $\begin{array}{c}\text { Cor aparente } \\
(\mathrm{nC})\end{array}$ & & & Não detectado & 15 \\
\hline Turbidez(UNT) & PONTOS DE & COZINHA DO & 0,32 & 5 \\
\hline $\begin{array}{c}\text { Cloro } \\
\text { residual(mg/L) }\end{array}$ & $\begin{array}{c}\text { ABASTECIMENTO } \\
\text { PARA CONSUMO } \\
\text { DIRETO E }\end{array}$ & $\begin{array}{l}\text { RESTAURANTE } \\
\text { ACADÊMICO E } \\
\text { COZINHA DA }\end{array}$ & Não detectado & 0,5 \\
\hline $\begin{array}{l}\text { coliformes totais } \\
(\mathrm{NMP} / 100 \mathrm{~mL})\end{array}$ & $\begin{array}{l}\text { PREPARO DE } \\
\text { ALIMENTOS }\end{array}$ & LANCHONETE & 261,3 & $\begin{array}{l}\text { Ausência em } \\
100 \mathrm{~mL}\end{array}$ \\
\hline $\begin{array}{c}\text { Escherichia coli } \\
(\mathrm{NMP} / 100 \mathrm{~mL})\end{array}$ & & & Ausente & $\begin{array}{l}\text { Ausência em } \\
100 \mathrm{~mL}\end{array}$ \\
\hline
\end{tabular}

\subsubsection{Monitoramento do consumo de água}

A solução de abastecimento do campus consiste de bombas submersas que direcionam os recursos hídricos para duas cisternas, posteriormente, a água é recalcada para caixa d'água. O controle de consumo de água é realizado pelo monitoramento das horas de operação da bomba responsável pelo enchimento da caixa d'água. Verificou-se que o consumo é variável e dependente das condições climáticas, os meses de maior consumo foram agosto e outubro de $2017 \mathrm{com}$, respectivamente, 1543,8 e $1422,9 \mathrm{~m}^{3}$. O consumo médio per capita observado em dez meses de monitoramento fora de 24,5 L.hab-1.dia ${ }^{-1}$.

\subsubsection{Vistorias na Estação de Tratamento de Esgotos}

A Estação de Tratamento de Efluentes do campus consiste de dois tanques sépticos de câmaras sobrepostas e dois filtros anaeróbios seguidos de sumidouros para disposição final. A vistoria comprovou existência de inconformidades estruturais e necessidade de manutenção relativa a descarga de lodo de fundo e coleta de escuma dos tanques sépticos. Em relação aos filtros anaeróbios, a canaleta de recolhimento dos efluentes tratados encontra-se em altura indesejável operacionalmente, o que configura inconformidade construtiva, além disso, os meios filtrantes requerem retirada e lavagem. Atualmente, em projetos de pesquisa da instituição, investigam-se soluções para adequação do tratamento de efluentes da instituição. A Figura 05 apresenta as evidências fotográficas do descrito. 
Joelma Lima Oliveira; Mailodovinci de Sousa Pereira; Janderson Cabral Barbosa;

Uriel Pereira da Silva Barbosa;

Letícia Lacerda Freire; Ana Beatriz Batista de Almeida; Monique da Silva Albuquerque;

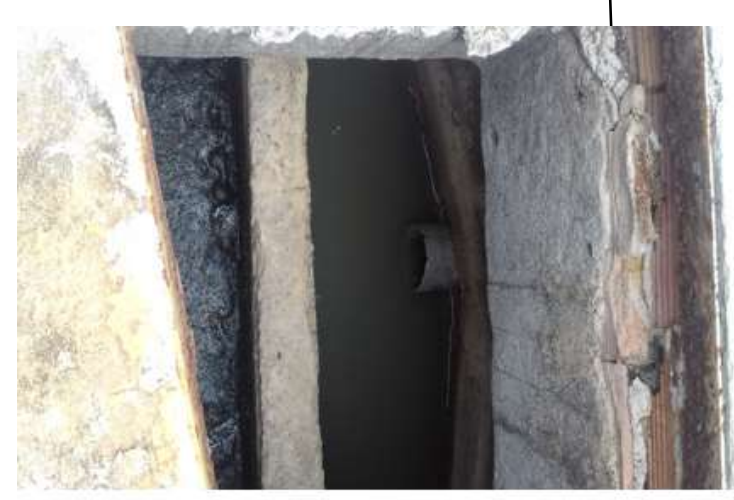

Entrada do tanque séptico com câmaras sobrepostas, com acúmulo de escuma na câmara interna.

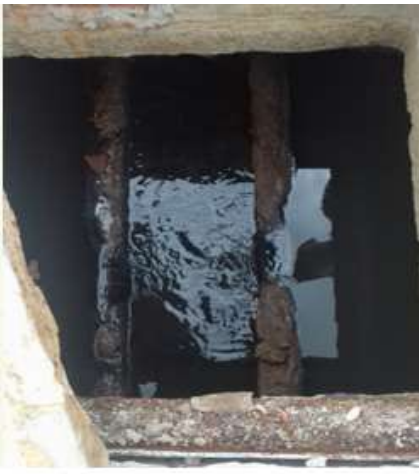

Não conformidade construtiva em canaleta de filtro anaeróbio

Figura 05: Evidências das constatações na ETE do campus.

\subsection{Ações da Gestão de Áreas Verdes}

\subsubsection{Estimativa das áreas verdes}

A estimativa das áreas irrigadas da instituição servirá de subsídio para controle do consumo de recursos hídricos por unidade de área. A Figura 06 apresenta graficamente as áreas identificadas. Para área total da instituição, obtevese $50.851 \mathrm{~m}^{2}$. As áreas verdes irrigadas respondem por área de $10.135 \mathrm{~m}^{2}$. Algumas das ações propostas ao grupo de atuação de áreas verdes demandam maior tempo e estão em desenvolvimento pela equipe de trabalho.

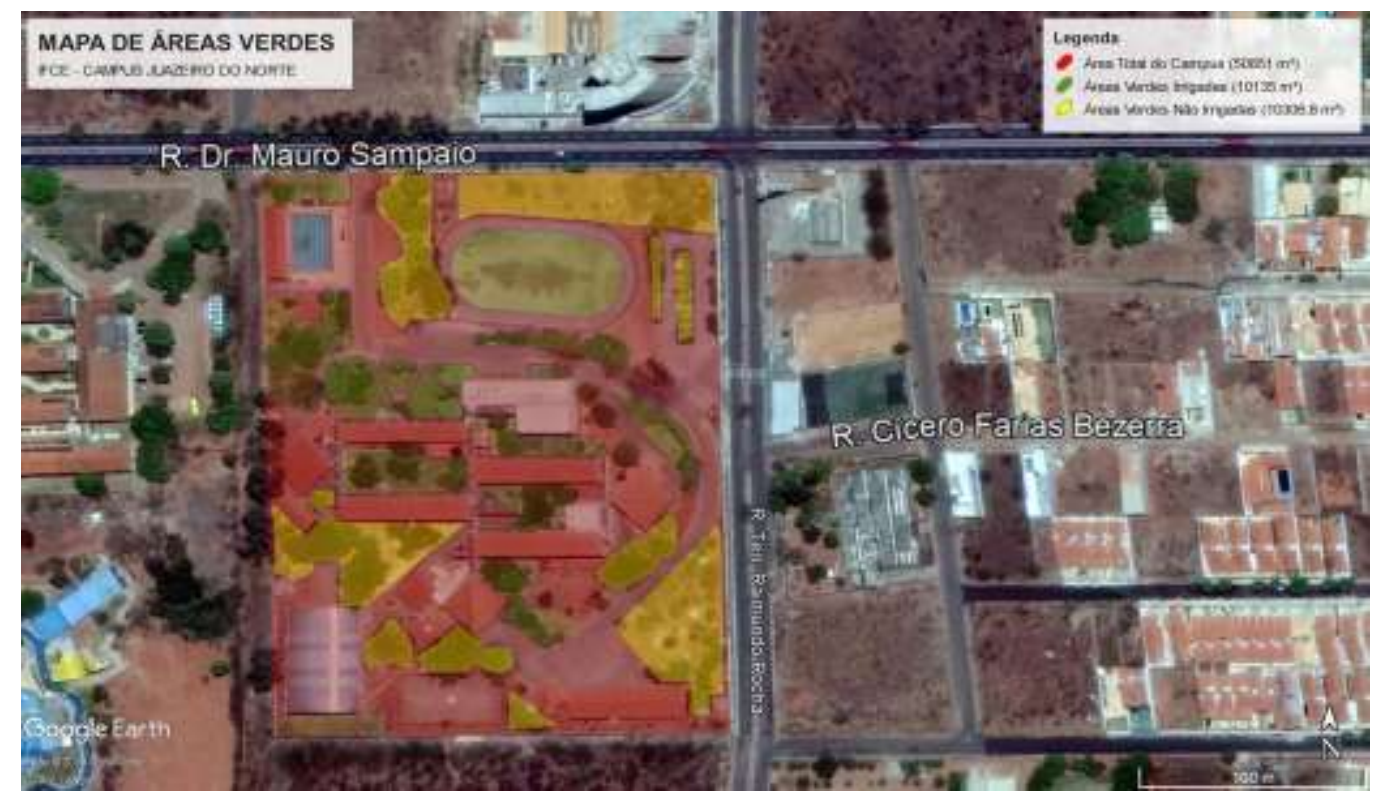

Figura.06: Estimativas de áreas do IFCE - campus Juazeiro do Norte.

Ciência e Sustentabilidade - CeS / Juazeiro do Norte, v. 4, n. 1, p. 115-132, jan/jun - 2018 


\section{CONSIDERAÇÕES FINAIS}

O Sistema de Gestão Ambiental, desde sua implementação, tem apresentado benefícios sociais, ambientais e econômicos para a instituição, contribuído para a redução de rejeitos na instituição, um maior controle em relação ao uso dos recursos hídricos, o acompanhamento qualitativo da água de abastecimento, redução do consumo de recursos energéticos, promoção da educação ambiental e monitoramento de áreas verdes da instituição.

O SGA ainda encontra desafios referentes à participação dos alunos da instituição em relação à adequada utilização dos coletores de coleta seletiva, bem como a conscientização com a redução dos gastos energéticos, uma vez que se faz necessário o comprometimento de todos para que o SGA atinja seus objetivos e sempre possa avançar na melhoria contínua, um dos seus princípios.

Em se tratando de apoio da gestão do campus, há apoio político para realização das atividades do SGA, no entanto, a disponibilidade de recursos ainda é limitada para que haja a ampliação da atuação do Sistema. Deve-se destacar ainda o caráter didático, principalmente para o curso de Bacharelado em Engenharia Ambiental, uma vez que os estudantes não só vivenciam práticas de gestão ambiental, mas também aplicam conhecimentos referentes aos resíduos sólidos, legislação ambiental, química analítica (determinação laboratorial de potabilidade), Microbiologia, Projeto de Sistema de Abastecimento de Água e Projeto de Estação de Tratamento de Águas Residuárias.

\section{REFERÊNCIAS}

ALBERTON, Anete. Meio Ambiente e Desempenho Econômico-Financeiro: o Impacto da ISO 14001 nas Empresas Brasileiras / Anete Alberton - Florianópolis, 2003.

BARATA, Martha Macedo de Lima; KLIGERMAN, Débora Cynamon; GOMEZ, Carlos Minayo. A gestão ambiental no setor público: uma questão de relevância social e econômica. Ciência \& Saúde coletiva. 2007, vol.12, n.1, pp.165-170. 
Joelma Lima Oliveira; Mailodovinci de Sousa Pereira; Janderson Cabral Barbosa;

Uriel Pereira da Silva Barbosa;

Letícia Lacerda Freire; Ana Beatriz Batista de Almeida;

Monique da Silva Albuquerque;

com ferramenta FMEA.InterfaceEHS-Saúde, Meio Ambiente e

Sustentabilidade.São Paulo, junho de 2016,vol.11, no1 .

DIAS, Juliana de Carvalho; XAVIER, Ana Clara Rodrigues; MARTINS, Luiza Dias; ENGELHARDT, Michelle Noronha. Gestão Ambiental na Petrobrás e CVRD. IV Congresso Nacional de Excelência em Gestão. Niteroi, RJ, 31 de julho, 01 e 02 de agosto de 2008.

ENGELMAN, Raquel; Guisso, Rubia Marcondes; FRACASSO, Edi Madalena. Ações de Gestão Ambiental nas Instituições de Ensino Superior. RGSA-Revista de Gestão Social e Ambiental.Jan-Abr 2009, vol.03, n¹, p.22-23.

GONÇALVES,Nadia Gaiofatto. Indissociabilidade entre Ensino, Pesquisa e Extensão: um princípio necessário. Perspectiva, Florianópolis, v.33, nํㅜ, p.12291256, set./dez.2015.

MAGRINI, Alessandra; POMBO, Felipe Ramalho. Panorama da aplicação da norma ISSO 14001 no Brasil.Gest.Prod. São Carlos, vol.15, n¹, p. 1-10, jan-abr.2008.

MUELLER, Charles C. Avaliação de duas correntes da economia ambiental: A escola neoclássica e a economia da sobrevivência. Revista de Economia Política. Brasília, vol.18, n², abril-junho de 1998.

MUELLER, Charles C. Os economistas e as inter-relações entre o sistema econômico e o meio ambiente. NEPAMA, departamento de economia da UNB. Brasília, abr/2004.

OLIVEIRA, Emídio Cantídio Almeida; SARTORI, Raul Henrique; GARCEZ, Tiago B. Compostagem.USP.Piracicaba, maio de 2008.

ROSA, Tânia Brum Della. Gestão Ambiental: Uma perspectiva sobre a responsabilidade socioambiental nas empresas. UNOPAR Cient. Londrina, vol.14, n2, p.255-258, set.2013. 